\title{
EL TESTAMENTO DEL ARQUITECTO CLEMENTE FERNÁNDEZ SARELA
}

\author{
Por \\ MIGUEL TAÍN GUZMÁN
}

Recientemente ha sido localizado en el Archivo de la Catedral de Santiago el testamento de Clemente Fernández Sarela, uno de los más emblemáticos arquitectos del Barroco gallego del siglo XVIII, autor de obras como la Casa del Deán, el Palacio de Fondevila y la Casa del Cabildo, en Santiago, o el Pazo de Sistallo en Lugo'. Su estudio ahora en estas páginas aporta nuevos e interesantes datos sobre su familia, sus propiedades y negocios, sus relaciones con otros arquitectos, sus instrumentos y materiales de trabajo, etc., y sus últimas obras arquitectónicas treś años antes de su muerte ${ }^{2}$.

\section{NUEVOS DATOS FAMILIARES Y BIOGRÁFICOS}

El 10 de julio de 1762, momento de redactarse el documento de su última voluntad, el artista se encuentra encamado por alguna enfermedad -ni siquiera puede firmar el testamento- en su casa del arrabal de Carrera del Conde, barrio que entonces pertenecía a la parroquia de Santa Susana.

\footnotetext{
${ }^{1}$ Deseo agradecer aquí a Javier Rey, Técnico Auxiliar del mencionado archivo, la cesión del descubrimiento de este documento para su estudio.

${ }^{2}$ Los datos del presente trabajo completan la monografía que sobre Clemente Sarela publicó en su día FOLGAR DE LA CALLE, Mª . DEL C., Los Sarela, Santiago, 1985.

"CUADERNOS DE ESTUDIOS GALLEGOS", Tomo XLV, Fascículo 110, Santiago 1998.
} 
En él especifica cómo quería se celebrase su sepelio, aunque no puedo determinar que se llevase a cabo conforme a sus deseos. Pretendía que le enterrasen vestido con el hábito de San Francisco bajo la lápida de su propiedad, la número cincuenta y uno, en la capilla de la Venerable Orden Tercera: a esta orden laica franciscana pertenecían gran número de artistas de la ciudad ${ }^{3}$. A la ceremonia del entierro solicitaba acudiesen sesenta sacerdotes, aparte del cura que debía oficiar, y una representación de los conventos de San Lorenzo, Santo Domingo, San Francisco y San Agustín ${ }^{4}$. A todas estas comunidades encarga, además, digan cada una treinta misas en sus respectivas iglesias, además de ochenta en la parroquia del arquitecto.

El maestro declara en el testamento haber estado casado dos veces. La primera con Pascua González de la Iglesia, con la que tuvo un hijo, Pedro Antonio Sarela, muerto a la edad de nueve años. Y la segunda, con Benita de Castro, con la que tiene entonces dos hijos, uno de dos años, María Francisca, y otro de cuatro, Fulgencio, y a la que dedica los máximos elogios, alabando lo «...ascendosso y economico de su experimentado gobierno» y pidiéndole perdón por los que califica «...algunos disgustos casseros». También alude a la existencia de dos parientes próximos, sus dos hermanos, Juan Sarela, catedrático de Filosofía en la Universidad de Santiago, y Francisco Sarela quien le debe dinero por diversas razones domésticas de poca relevancia.

\section{PROPIEDADES Y NEGOCIOS}

Muy variopintas son las propiedades que declara poseer el artista. También son curiosos algunos de sus negocios, muestra de los múltiples recursos a los que debía dedicarse un arquitecto de la época para poder mantener a su familia.

Tiene alquiladas dos casas de su propiedad, una en la Rúa Nova por cincuenta y seis ducados al año, y otra de una altura en la Rúa de las

\footnotetext{
${ }^{3}$ Sarela ingresó en 1737 . Ibidem, 39 y 56.

${ }^{4}$ El 30 de junio de 1765 Sarela es efectivamente enterrado en la capilla de la V.O. Ibidem, 56.
}

"CUADERNOS DE ESTUDIOS GALLEGOS", Tomo XLV, Fascículo 110, Santiago 1998. 
Huertas a un tal Antonio López por siete ducados y medio al año, con un huerto por el que paga treinta y tres reales ${ }^{5}$.

Presta dinero en ocasiones y es de suponer que con afán de obtener un cierto beneficio económico. Mateo de Romarís, Pedro Caxarville, Alonso Mogo y Antonio Rosua le deben el importe del Voto de los años 1758 y 1759.

Sorprende su dedicación a la ganadería pues dice cuidar de un pequeño rebaño de cinco cabras «con una cría a ganancia» propiedad de María Figueiras. En cambio, una yegua y una potra de su propiedad son cuidados por Francisco Xermiñas del que dice le debe dinero por las ganancias de un «macho». Otros acreedores son un tal Amaro de Mons, herrero compostelano, por la entrega de un «jaco», y Antonio Fernández por el alquiler durante veinticuatro días de una mula. Con las pieles curtidas de esos y otros animales parece también que obtenía algún tipo de beneficio, enviándolas a Conxo para tal efecto.

El poseer caballo propio le es muy útil cuando ha de concurrir a la subasta de una obra en algún punto lejano de la geografía gallega, como sucedió cuando se hizo el concurso público para construir el edificio del Cuartel de Santiago en la ciudad de A Coruña.

\section{SU RELACIÓN CON LUCAS FERRO CAAVEIRO}

Sarela declara haber prestado respetables sumas de dinero en diferentes momentos al también arquitecto Lucas Ferro Caaveiro para que éste pudiese cumplir con sus deudas. Nuestro artista paga los pontones de la casa del canónigo Francisco Villarino en la Plaza del Toral y de la casa de la Tenencia de Arcos da Condesa (Caldas de Reis), ambas reparadas por Caaveiro, así como los gastos del desplazamiento a la ciudad de A Coruña para participar en la subasta de la construcción del cuartel antes mencionado, viaje que, además, realizan juntos ${ }^{6}$.

Tanto los préstamos como su viaje en común pueden apuntar a la existencia de una relación no tanto de amistad como de apoyo económico.

\footnotetext{
${ }^{5}$ Quizás sea la que adquirió en 1752. Ibidem, 49.

${ }^{6}$ Según el documento, Caaveiro junto con Cayetano Gil consiguieron la adjudicación de la obra.
}

"CUADERNOS DE ESTUDIOS GALLEGOS", Tomo XLV, Fascículo 110, Santiago 1998. 
Dicha relación parece venir de muy lejos, dado que ambos trabajan juntos en la construcción de varios edificios de la ciudad de Santiago.

\section{INSTRUMENTOS DEL OFICIO Y MATERIALES PARA SUS OBRAS}

Varios son los instrumentos relacionados con la profesión de arquitecto que posee Sarela, como son tres cuñas de hierro para arrancar la piedra y de «...pesso cada una de siete libras» y un caldero de cobre que compró para sus «...menesteres en la assistencia de la obra de la referida capilla de Nuestra Señora del Rial». Paradójicamente, ambos útiles son más propios de un maestro cantero que de un arquitecto tracista y director de obras, y denotan en sí las indistintas facetas del trabajo diario que el artista debía afrontar.

El documento también alude a la adquisición por el maestro en Ferrol de «un pie de gato», parte de la llave de algunas armas de fuego que quizás llevase consigo para protegerse en sus viajes por la geografía gallega.

La piedra, la madera, la cal, la arena, los clavos o «botones» y las cuerdas de cáñamo o «guindaletas», necesarios para sus actividades, eran adquiridas directamente por el propio Sarela, quien también se encargaba de su transporte a pie de obra. Para otro tipo de materiales como pueden ser los herrajes -cerraduras, rejas, picaportes, etc.- concierta su fabricación con un artífice especializado y poseedor de una fragua. Cuando contrata vigas de castaño suele hacerlo ya con unas medidas de longitud predeterminadas según la fábrica de que se trate. Así lo hizo con el carpintero compostelano Enrique Beloso a quien pidió comprase y transportase maderas desde los bosques hasta Santiago.

\section{SUS ÚLTIMAS INTERVENCIONES ARQUITECTÓNICAS}

El testamento aporta una información muy valiosa sobre cuales fueron las últimas obras en que estaba trabajando el arquitecto en el momento de caer enfermo -y por las que se le debían distintas cantidades dinero-, su localización geográfica y su carácter. 
En la ciudad de Santiago declara ser el autor de la de la casa del maestro sastre Vicente de Puga «...desde los simientos, ideando sus divisiones $y$ disposiciones...» y horadando en una de sus paredes medianeras dos alacenas de cantería «con sus relieves de media caña y filete». Desgraciadamente no señala en que calle construyó el inmueble por lo que no se puede saber si subsiste actualmente. También dice haber intervenido en la fábrica de la casa del mercader de paños Francisco García Pan, sita en la «Plaza Publica de la expressada ciudad». Si se refiere a la antigua Plaza del Campo -hoy Plaza de Cervantes- en la que estaba el edificio del Ayuntamiento y donde se celebraban los actos públicos de Santiago -la lectura de pregones, etc.- dicha casa puede ser la que en la actualidad ostenta el número 8, pues así parece indicarlo el vocabulario ornamental de su fachada (Fig.1). De menor repercusión es su remodelación de la casa, hoy desaparecida, de Alonso Romero en la Calle del Hórreo. Sarela

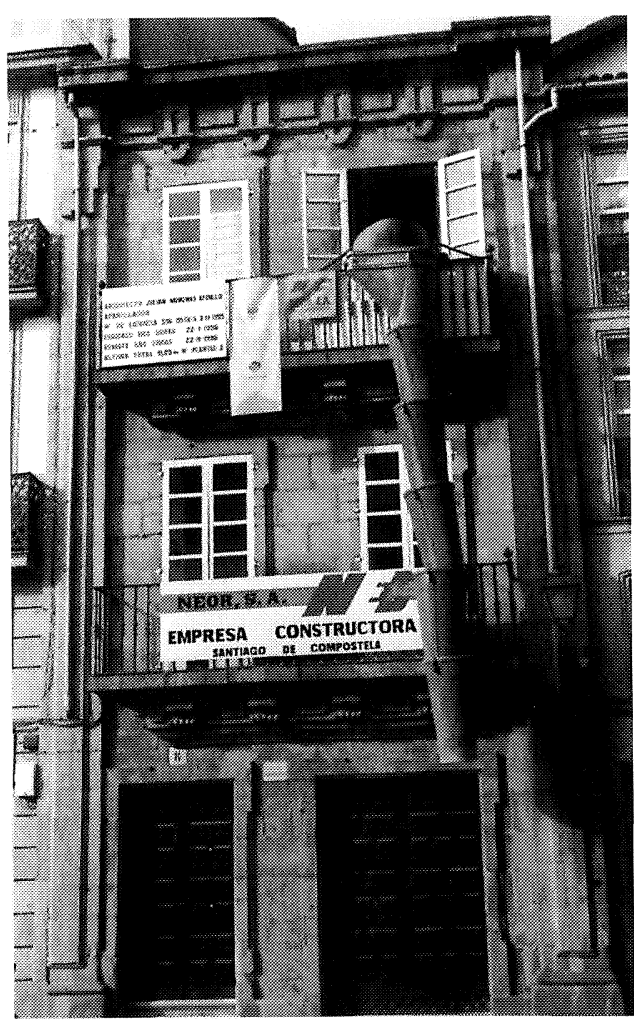

Fig. 1.- Casa ${ }^{\circ} 8$ de la Plaza de Cervantes, en Santiago de Compostela.

"CUADERNOS DE ESTUDIOS GALLEGOS", Tomo XLV, Fascículo 110, Santiago 1998. 
proyecta y concluye aquí una puerta de cantería en la entrada, las nuevas escaleras interiores, dos chimeneas y todas las habitaciones de la parte posterior del edificio. La última construcción de una vivienda en la que declara haber aplicado su «assistencia personal» es en la de Valentín Sánchez Boado, sita en la Rúa de Casas Reales, edificio que Folgar de la Calle ha identificado como el actual Palacio de Fondevila ${ }^{7}$.

Otras intervenciones de carácter menor, pero no por ello despreciables pues son una clara muestra de la multiplicidad de trabajos a los que se dedicaba un arquitecto compostelano del momento, son los encargos de la colocación de una lápida de cantería para sepulcro de Pedro Torreiro en el claustro de la Catedral y la fabricación de una chimenea en la casa del mercader Domingo García en la Rúa del Villar.

Su capacidad como tracista también queda plasmada en el documento pues en él declara ser el autor de las plantas del llamado «convento nuevo», con cuya fábrica dice estar corriendo en ese momento. Desconozco a que edificio se refiere, aunque quizás sea el del convento de San Francisco, el de Conxo, entonces con partes en construcción ${ }^{8}$, o el de la Compañía de María*.

Fuera de Compostela sólo se señala la autoría de Sarela en una obra. El canónigo de la Catedral de Santiago, José Jiménez, es el cliente que le encarga la traza y construcción de la capilla de Nuestra Señora del Rial, sita en el templo parroquial de San Ourente de Entís (Outes). En un primer momento la edificación del edificio se hace a jornal diario, sistema que no debió de funcionar o ser muy caro para el canónigo pues al cabo de un tiempo se decidió cambiar, comprometiéndose el arquitecto a terminar la obra por un precio fijo y único -600 ducados-, eso sí, siempre que corriese por cuenta del religioso los gastos del personal y de los materiales.

Muchas han sido las pesquisas que he debido hacer para averiguar que fue de la capilla de Sarela. Hoy en día la antigua iglesia parroquial de San Ourente de Entís es una ermita dedicada precisamente a Nuestra Señora

${ }^{7}$ Dicha autora documenta que se construyó siguiendo las trazas del propio Sarela. Cfr. FOLGAR DE LA CALLE, $\mathrm{M}^{\mathrm{a}}$. del C., op. cit., 55 y 118-128.

${ }^{8}$ FOLGAR DE LA CALLE (Ibidem, 129-132) cree posible la intervención del arquitecto en la construcción del claustro y la fachada principal del convento de Conxo.

* Cfr. FOLGAR DE LA CALlE, Ma del C., «Convento-colegio de la Compañía de María», Santiago de Compostela, Patrimonio Histórico Gallego, A Coruña, 1993, 422-428.

"CUADERNOS DE ESTUDIOS GALLEGOS", Tomo XLV, Fascículo 110, Santiago 1998. 


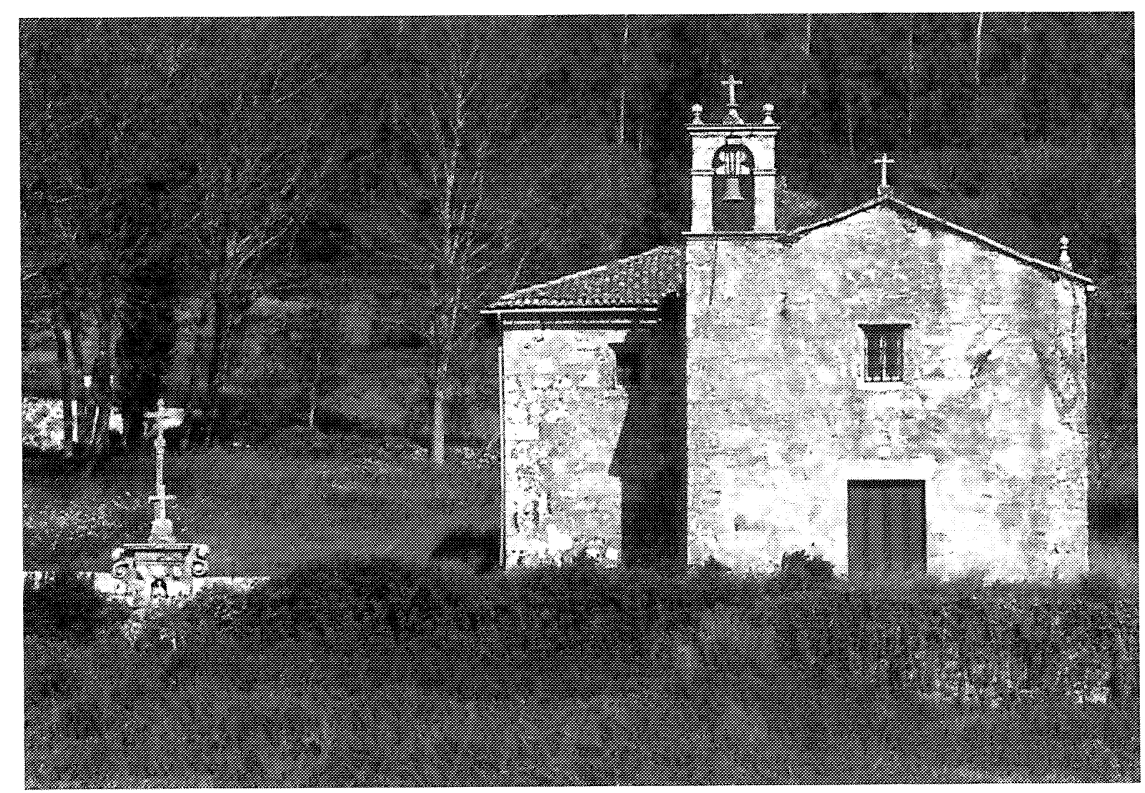

Fig. 2.- Capilla de Nuestra Señora del Rial, en Ourente (Serra de Outes).

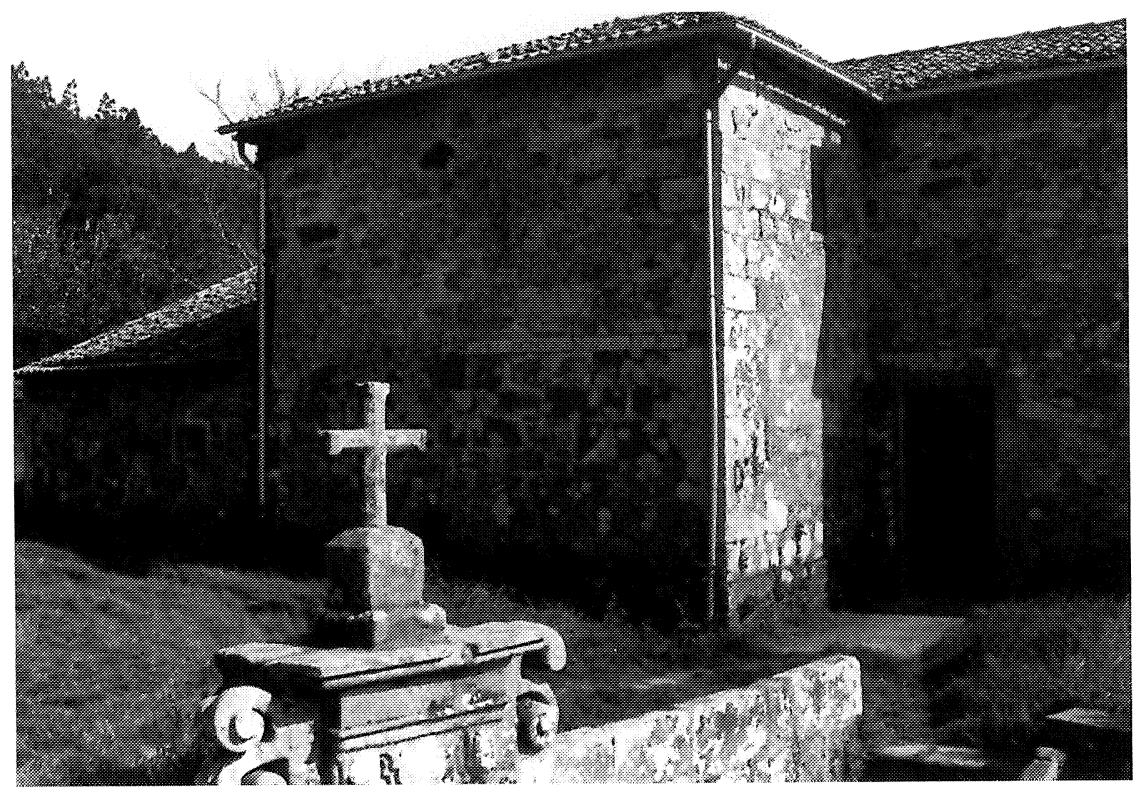

Fig. 3.- Vista exterior de la Capilla Norte, en Nuestra Señora del Rial. 
del Rial ${ }^{9}$. Edificio sencillo de una sola nave, presenta al Norte una capilla que por sus características bien pudiera ser la de nuestro artista (Figs.24). Es de planta cuadrangular, construida con buenos sillares de cantería y cubierta por una magnífica bóveda de arista, sostenida por pilastras toscanas. Recibe luz en el interior a través de dos ventanucos rectangulares abocinados, situados uno al Este y el otro al Oeste. El tramo inmediato de la nave de la iglesia presenta el mismo tipo de cubierta y soportes que la capilla: quizás esta parte del edificio se deba al mismo arquitecto. Tanto en el interior como en el exterior del recinto impera la austeridad. Carece de la típica ornamentación que identifica las intervenciones de Sarela. No así la Fuente del Santo dos Croques, situada dentro del enclave parroquial, y decorada con las características placas recortadas del maestro (Fig. 5).

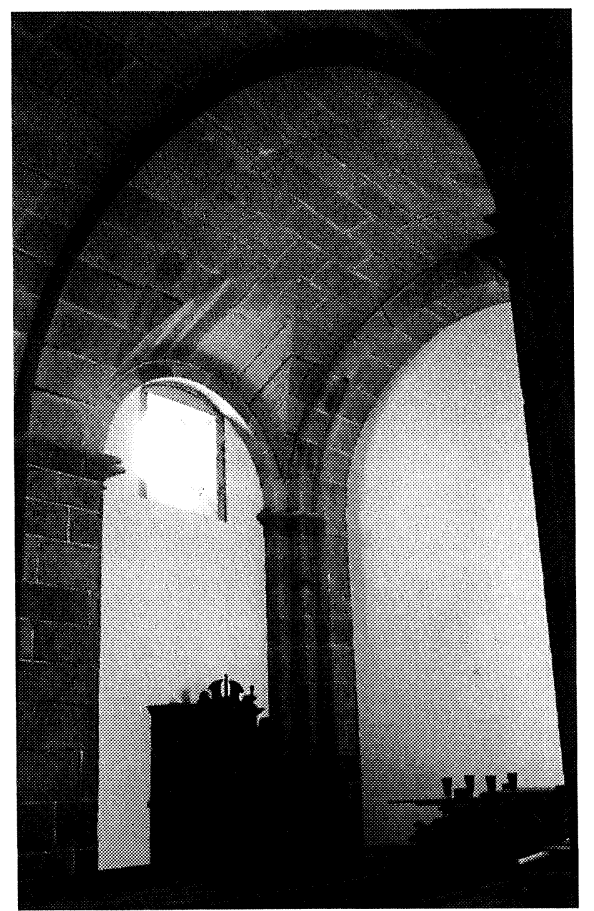

Fig. 4.- Vista interior de la Capilla Norte, en Nuestra Señora del Rial.

${ }^{9} \mathrm{La}$ actual iglesia parroquial es un edificio próximo de finales del siglo XVIII.

"CUADERNOS DE ESTUDIOS GALLEGOS", Tomo XLV, Fascículo 110, Santiago 1998. 


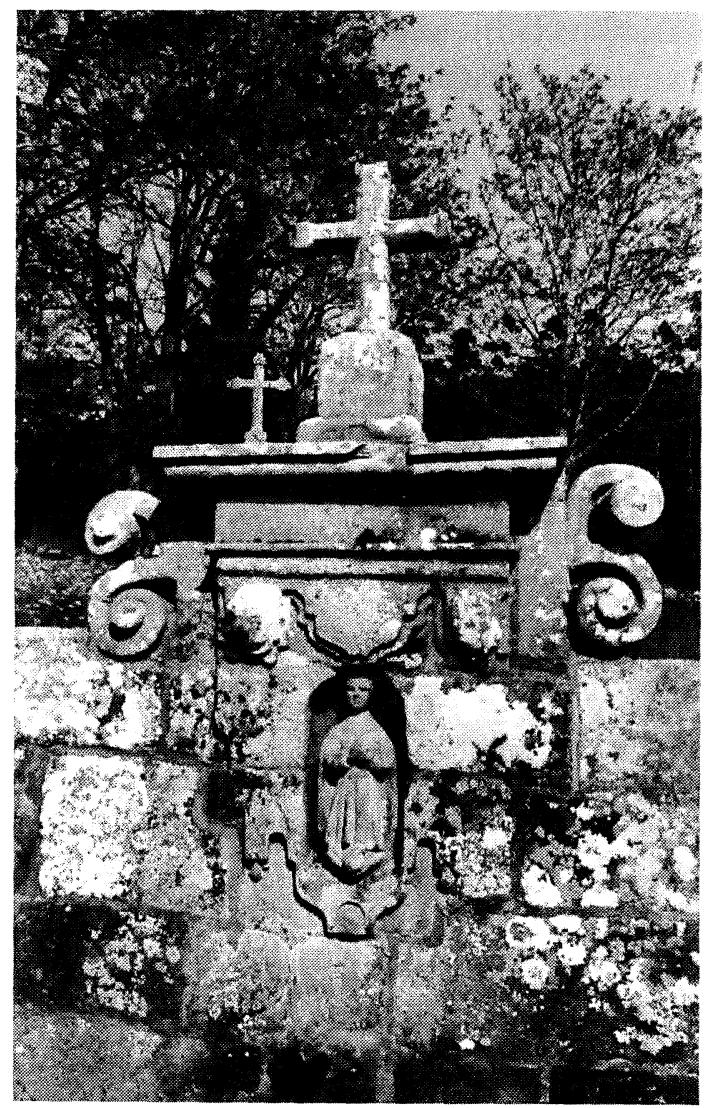

Fig. 5.- Fuente del Santo dos Croques, en Nuestra Señora del Rial.

El testamento de Clemente Sarela es un documento excepcional para perfilar la personalidad de este genial arquitecto y de capital importancia cuando se redacte una futura Sociología del Arte Gallego del siglo XVIII. En él vemos las diversas ocupaciones e inversiones que se ve obligado a practicar uno de los más grandes artistas de la piedra de esa centuria. También sirve para entender como un gran arquitecto no sólo traza y dirige grandes empresas arquitectónicas, sino que no desprecia en absoluto dedicarse a pequeñas «chapuzas» -construir una alacena o una chimenea- para poder obtener unos ingresos extra. De ello es fiel reflejo no sólo la lista de obras que enumera sino también los útiles e instrumentos del oficio a los que alude.

"CUADERNOS DE ESTUDIOS GALLEGOS", Tomo XLV, Fascículo 110, Santiago 1998. 


\section{APÉNDICE DOCUMENTAL}

\section{Testamento que otorgó Clemente Sarela.}

In Dei Nomine. Amen.

Sea notorio a todos lo que la presente Carta de Testamento y última voluntad vieren como yo Clemente Sarela, maestro de arquitectura, vecino del barrio Carrera del Conde, arrabal inmediato a la ciudad de Santiago, parroquia de Santa Susana de Adentro, hallándome postrado en cama de enfermedad natural, que Dios nuestro Señor fue servido darme, aunque en mi juicio y entendimiento natural, creyendo, según firmemente creo, en los misterio de la Santíssima Trinidad, Padre, Hijo, y Espíritu-Sancto, tres personas distinctas, y un solo Dios verdadero, y en todo aquello que tiene, cree, y confiesa la Santa Iglesia Cathólica, Apostólica, Romana, en cuya fee he vivido y protesto morir, invocando para ello el auxilio del Espíritu-Santo; y elixo por mis protectores a la bienaventurada siempre Virgen María, gloriosos apóstoles San Pedro y San Pablo, al Santo Angel de mi guarda, al de mi nombre a los santos Patriarcas, Profetas, Mártires, Confessores, Vírgines y más de la Corte celestial, vajo cuyo amparo, para que mis cosas queden dispuestas al mayor honor y gloria de Dios nuestro Señor, hago y ordeno este mi testamento en la forma que sigue:

Mando mi alma a Dios nuestro Señor, y el cuerpo a la tierra de que fue formado, el que se amortage en hábito de sayal de mi Padre San Francisco, y sepulte en la Capilla de la hermandad de su Tercera Orden de la dicha ciudad; y en sepultura cuya lápida se haya guarismada con el número cinquenta y uno; y assistan a mi entierro sessenta sacerdotes, además del cura, con las quatro comunidades, que componen San Lorenzo, Santo Domingo, San Francisco, y San Agustín, y se celebren por mi alma por una vez, y [con la] limosna acostumbrada, ducientas missas rezadas, de cuya limosna al respecto de treinta missas, que se digan en cada una de dichas quatro comunidades; y la de las ochenta restantes a disposición del cura de dicha mi Parroquia de santa Susana: y quanto a la disposición, con que se haga mi séptimo día, y cavo de Año, lo dexo al arbitrio de los cumplidores, que en este mi testamento eligiré.

Mando a la Santa Cruzada redempción de cautivos lo acostumbrado por una vez, con que les aparto de mis bienes.

"CUADERNOS DE ESTUdIOS GALLEGOS", Tomo XLV, Fascículo 110, Santiago 1998. 
$Y$ declaro, para descargo de mi conciencia, averse puesto por Don Joseph Giménez Canónigo, capitular en la Santa y Apostólica Iglesia de dicha ciudad de Santiago, a mi cuidado, y obligación la fábrica y obra de la capilla de Nuestra Señora del Rial, sita dentro de la parroquial iglesia de Santo Ourente de Entínez, para lo que me fue preciso passar a aquel parage y formar la planta, prosiguiendo en parte de la fábrica de dicha obra por sueldo diario, hasta que en el año passado de mil sietecientos cinquenta y ocho me constituí a concluirla en la cantidad de seiscientos ducados por todo lo restante que faltaba, quedando a cargo del dicho Don Joseph costear fuera de aquel principal la conducción de piedra de cantería, pissarra, sirvientes, estadas, maderas de armazón y más andamios, dar de comer y beber a los carreteros por la conducción de dichas maderas desde la feligresia de Santa Eulalia de Río-Abesso a la obra, sobre cuyo cumplimiento y seguro se formó papel, firmado mío y de dicho Don Joseph, que para en su poder; y no obstante esto, yo he suplido todos aquellos costes, que importaron más de trescientos ducados, sin ser de cuenta de mi principal, según el dicho contrato, que me está por satisfacer, sobre que hable a voca y por escrito a dicho Don Joseph; y que para su mayor satisfación, y a mi dármela, mandase reconocer la obra, lo que se ha diferido por sus ocupaciones: tengo la confianza en su proceder, de las disposiciones para que se reconozca aquella obra y se satisfaga a mis herederos lo justo, teniéndose pressente, lo que en este asumpto dexo declarado, y mi assistencia personal para la mejor, y más acertada disposición en aquella citada obra.

Yten digo, que a instancia del maestro sastre Vizente de Puga, vecino de la referida ciudad de Santiago, he asistido por mi arte de arquitectura a la fabrica de su cassa, que vive, desde los simientos, ideando sus divisiones y disposiciones a la mejor perfección de sus servidumbres, por lo que soy acreedor, y a mí el sobredicho deudor, de quinientos reales vellón, con ciento y cinquenta reales de dicha moneda, por el reconocimiento y estado, que a su pedimiento he tomado en la pared que de dicha cassa hace medianía a la fábrica nueva de otra cassa del cavallero regidor Don Juán Zisneros, con cuyo motivo, también he ideado y costeado en aquella pared, para servidumbre de dicha cassa del maestro Puga, dos alacenas de cantería con sus relieves de media caña y filete, de que me debe liquidamente quinientos y tres reales, quedándole rebajados noventa y siete de quinze carretos de cantería costeados únicamente por

"CUADERNOS DE ESTUDIOS GALLEGOS", Tomo XLV, Fascículo 110, Santiago 1998. 
el sobredicho, cuyas partidas en el todo componen la de un mil ciento cinquenta y tres reales vellón de que legítimamente me es deudor; y assi lo declaro, por descargo de mi conciencia, y que sean cobrados por mis herederos.

Item, para que conste, digo tener de María Freyre, viuda vecina de Santa María de Figueyras, cinco cabras con una cría a ganancia, de lo que a mayor abundamiento se hallará razón en mis papeles.

Ytem, declaro aver assistido personalmente, por mi pericia, por llamamiento del mercader de paños, y otros géneros, Don Francisco Garzía Pan, a la formación y disposiciones de servidumbres de la cassa que fabricó y está viviendo en la Plaza pública de la expressada Ciudad, de la que tomé y reconocí los estados con las de los vezinos medianiles; y de uno, y otro equitativamente meresco mil y quinientos reales vellón: soyle deudor, para quenta de ellos de partida, que líquidamente, por lo pronto, no estoy acordado; si que de la que sea, le hize obliga firmada mía, la que desquente, y satisfaga a mis herederos el residuo.

También me debe Enrrique Beloso, carpintero vecino de esta ciudad, ciento quarenta y ocho reales vellón que le entregué para compra de maderas de castaño y su conducción a dicha ciudad desde los parages; a quien di las medidas para la longitud de ellas y más necessario a su servicio; y en medio de averle afianzado en aquel cumplimiento Bernardo Rosende, del mismo oficio de carpintería y vecindad de la expressada ciudad, no ha correspondido faltando en un todo al trato, sin averme dado satisfación de dichos ciento quarenta y ocho reales; lo que dexo declarado, para que mis herederos los perciban del referido, o de su citado fiador.

También me debe Doña Rosa Torreyro, vecina de la misma ciudad de Santiago, cinquenta reales vellón procedidos de la lápida que, de su orden, he costeado y está puesta sobre la sepultura de Don Pedro Torreyro, su hermano difunto, en el claustro de la Cathedral de dicha ciudad, cuyo importe cobren mis herederos.

Item, me debe Domingo Garzía, mercader y vecino de la expressada ciudad, ducientos y más reales procedidos de todos materiales, que le he costeado en la fábrica de la chiminea de la cassa que vive en la Rúa del Villar.

Item me debe Don Alonso Romero, vecino de la citada ciudad, ochenta reales procedidos de la fábrica de una puerta de cantería en su cassa

"CUADERNOS DE ESTUDIOS GALLEGOS", Tomo XLV, Fascículo 110, Santiago 1998. 
de la calle del Orreo para la que he costeado las piedras, maderas y más materiales necessarios, con más setenta reales que también costehé por el marco de la vidriera que da luz a la escalera de aquella citada cassa; cuya escalera, y su formación, también le he proyectado, con dos chimineas, y disposiciones de viviendas y servidumbres, en la parte posterior de la misma cassa, assistiendo por mi persona todo lo precisso a aquellas operaciones; por lo que soy acrehedor y me debe trescientos reales vellón, que juntos a las dos partidas antecedentes, componen en principal, quatro cientos, y cinquenta reales del dicho vellón, los que diversas veces le pedí, quedando por satisfacérmelos, lo que hasta ahora no ha cumplido, y es mi voluntad se cobren por mis herederos.

Item, me debe Don Lucas Ferro Caaveyro, vecino de dicha ciudad, cinquenta y ocho reales, que le entregué para cumplir con un fraguero llamado Torre por número de pontones, para reparar la cassa en que vivió el canónigo capitular Don Francisco Villarino, difunto, sita en la Plaza del Toral; diez y seis reales para satisfacer la paga de unos pontones a un vecino de la Ulla, los que sirvieron, para reparar la cassa de Tenencia de Arcos de Condessa, adelante de la villa de Caldas; ciento y cinquenta reales, que por dicho Caaveyro, y por Cayetano Gil, también vecino de la referida ciudad, he pagado a Don Angel Fonte-Coba, actual síndico de San Francisco en ella, los que este les avía prestado en la ciudad de la Coruña, a tiempo que los dos se hallaban en ella a poner, y rematar la obra del quartel de dicha Ciudad de Santiago; setenta reales y veynte y dos maravedices, que por los dos suplí en el gasto y alimento de dos cavallerías, y del alquilador, que cuydaba de ellas, y en su herrage, interin los referidos hicieron estancia en dicha ciudad de la Coruña a la pretensión de la obra del expresado Quartel, y en esta partida no se incluye el gasto de mi cavallería, aunque se hallaba con las dos de aquellos; doce reales, que por ellos suplí, para quenta del coste del refresco en el día que otorgaron en dicha ciudad de Santiago la obligación de la fábrica del dicho quartel que en ellos se avía rematado; cuyas partidas componen trescientos seis reales, y veinte y dos maravedices, de que no se me ha dado satisfación, déxolo declarado, para que mis herederos los cobren.

También declaro, aver prestado a Don Antonio Gómez, músico tiple en la Cathedral de dicha ciudad de Santiago, y tiene en su poder, tres cuñas de hierro para arranque de piedra, pesso de cada una de siete

"CUADERNOS DE ESTUDIOS GALLEGOS", Tomo XLV, Fascículo 110, Santiago 1998. 
libras, y en valor, las tres, treinta reales, las que mis herederos recojan, o dicho importe; y también recojan un vale, que el sobre dicho, en su poder, firmado mío, tiene, por ducientos reales, que le tengo satisfecho por mano de Don Pedro García, mayordomo de la Messa Capitular de la Santa y Apostólica Iglesia de Santiago.

Débeme Francisco Xermiñas treinta y tres reales [de] vellón por axuste de cuentas de las ganancias de un macho, y me tiene en su poder una yegua y una potra, según todo consta de papeles que se hallan en mi poder.

También me debe Matheo de Romarís, Pedro Caxarville, Alonso Mogo, y Antonio Rosúa, vecinos del Préstamo de Sales, los votos del año de cinquenta y ocho, a cobrar en el de cinquenta y nueve, y los de este cobrados en sessenta, de que hasta ahora no me han dado quenta segun a ello estan obligados por papel que con sus firmas existe en mi poder, debiendo ser cobrados los votos de cinquenta y ocho vendidos en cinquenta y nueve a cinco reales, y medio; y los de cinquenta y nueve vendidos en se-ssenta a siete reales: es mi voluntad ajusten y paguen, según aquí declaro.

También digo deberme Amaro de Mons, herrero vecino de esta ciudad, ochenta reales, resto de un jaco que me compró y quedó debiendo Antonio de Mons, su padre difunto, cuya herencia recayó y recogió dicho Amaro, su hijo, al que entregué por quenta de la obra y herrages para la cassa del médico Don Pedro Bedoya ciento y cinquenta reales vellón, sin que para quenta de ellos dicho Amaro de Mons huviesse fabricado más herrage que un marco de red para el tejado y siete libras de palmelas para la puerta de la calle, sin aver hecho otra cosa, y por falta de cumplimiento me fue precisso tratar sobre las más herrages y que las fabricasse, según lo ha hecho, Lásaro de Noya, herrero; y además de lo referido, también se me es deudor el Amaro de Mons, de diez y siete reales, catorce de ellos procedidos de dos ferrados de centeno, y los tres restantes de dos hases de paja triga, cuyas partidas suman ducientos quarenta y siete reales, de los quales, rebajando el importe del dicho marco de red, las siete libras de palmelas, y veinte reales de la hechura de una cerradura, lo más restante lo satisfaga a mis herederos, y estos los cobren del sobre dicho, que assí es mi voluntad.

También declaro vivir de mi orden en la calle de las Güertas Antonio López una cassa terrena, en cantidad de siete ducados y medio al año, a

"CUADERNOS DE ESTUdiOS GALLEGOS", Tomo XLV, Fascículo 110, Santiago 1998. 
cuyo respecto me está debiendo año y medio, cumplido en San Juan próximo, passsado del año corriente, y además de ello treynta y tres reales por una leyra de güerta separada de la correspondiente a la misma cassa, que de uno y otro usa el sobredicho.

Item, me debe Fernando Sarela, mi hermano, treinta y seis reales y medio que importan treinta y tres libras de bacalao que le entregué; más treinta i cinco reales y quatro maravedises que he costeado en ropa de vestir y más menesteres para ello, a una criada que me trujo el sobredicho, casa a su satisfación, y confianza, afianzándola en ello, y en su servicio, y sin averme hecho alguno, se ha escapado con aquel adelantamiento; también me debe dicho mi hermano treynta reales que presté a su muger, para menesteres casseros, cuyas partidas componen ciento un reales y veynte $i$ un maravedís vellón, para cuyo cobro los dexo declarados.

Item, me debe Don Valentín Sánchez Boado una arroba de bacalao, su importe treynta y quatro reales $i$ medio; y por las plantas que formé para el convento nuevo en término de dicha ciudad de Santiago, con cuya obra estoi corriendo, me es deudor en más de tres cientos ducados, y lo que tengo recibido del sobredicho por la assistencia personal a aquella obra dando las disposiciones, y mi travajo constará de recibos, que le tengo dados; y por la assistencia personal mía a disponer las viviendas, servidumbres, y más oficinas en la formación de su cassa, sita en las Cassas Reales de dicha ciudad de Santiago, se ha convenido conmigo en darme cien ducados vellón a quenta de los que recibí cinquenta, y me resta debiendo otros cinquenta; todo lo que así dexo declarado por descargo de mi conciencia, y que mis herederos sean satisfechos.

Item, me debe dicho Cayetano Gil, de quien ya dexo hecho expresión quarenta reales [de] vellón que le presté por mano de Andrés de Albeyra, carpintero, por quien me los mandó pedir, e yo varias veces el dicho débito al sobredicho por Antonio Fontao, cantero, no hubo forma me los pagasse, ni lo más que dexo esplicado, quiero se cobre uno y otro.

Item, me debe Esteban de Otero, que sirve de criado al administrador de rentas provinciales en dicha ciudad de Santiago, veinte i quatro reales [de] vellón, los que afiancé y pagué por un hermano suyo, siendo presencial Don Esteban de Barjas, executor de los mandatos del assistente de dicha Ciudad.

"CUADERNOS DE ESTUDIOS GALLEGOS", Tomo XLV, Fascículo 110, Santiago 1998. 
Item, declaro que por la cassa que en la Rúa Nueva vive de mi orden y por arriendo Domingo Candal, armero, se me pagan treynta i seis ducados al Año, y por la de su trasera veinte ducados.

También declaro aver remitido y costeado a Don Jacinto de Prado, vecino de la villa del Ferrol, una romana que excede el pesso mayor más de diez y siete arrobas, su echura a todo coste cien reales, los que el sobredicho tiene a quenta de trescientos y más reales vellón, importe de cuerdas, botones, y un pie de gato que el año próximo passado de sessenta y uno compré en la dicha villa del Ferrol, cuyos botones y cuerdas los conduxo desde la ciudad de la Coruña Bernardo Pérez hasta el lugar de Buscás donde los dexó, y estuvieron varios meses, de las que me faltaron muchas guindaletas, y un botón, el precio de este quarenta reales y otros quarenta el de las guindaletas, por cuyo hecho le tengo por satisfacer dicha condución, hasta tanto que me concurra con la entrega de todo, para cuya quenta, le entregué quatro rreales antes que fuesse a buscare lo referido.

Ytem, me debe Antonio Fernández, alquilador vecino de dicha parroquia de Santa Susana, sessenta y seis reales [de] vellón procedidos del alquiler de una mula mía que, con engaño, me ha pedido, a ocuparla el término de veinte y quatro días, y únicamente la ha empleado en viage desde la ciudad de Santiago a la villa de Pontevedra con mucho pesso de alforxas y maleta, y en la misma conformidad lo ha hecho, quando la restituyó, faltosa de todas herraduras y con distintas amatas haviendo quedado conmigo de cuydarla como a la suya, sin largarle pie, experimentándose de todo ello lo contrario.

Ytem, me está debiendo Cayetana López, vecina de dicha ciudad, muger de Casimiro, cuyo apellido ignoro, reales [de] vellón, que tuvo de coste un cordial que se le ha recetado, y por ella pagué al Padre Phelipe, a cuyo cargo corre la botica del Colegio de la Compañía.

Item, declaro me tiene Pasqua Gallarda, vecina de Santa Tassia, en su poder un caldero de cobre que me costó veinte y quatro reales, y compré para mis menesteres en la assistencia de la obra de la referida capilla de Nuestra Señora del Rial, el que quiero se recoja del poder de la sobredicha, y se perciba de Antonio do Rego, vecino de Santo Ourente de Entines, el ymporte de veinte y seis quartillos de vino, al respeto de quatro quartos y medio cada uno, que por el sobredicho suplí a tiempo que se celebró una missa cantada en aquella capilla a devoción del sobredicho.

"CUADERNOS DE ESTUDIOS GALLEGOS", Tomo XLV, Fascículo 110, Santiago 1998. 
Item, declaro para que conste, tengo para el beneficio de curtir dos pieles, una de buey i otra de baca, esta en poder de Juan de la Yglesia, y aquella en el de un fulano mariño, que se dice son vecinos de Santa María de Conxo, para cuyo fin se los conduxo de mi orden, Estevan de Otero persona de quien ya dexo dado razón.

También declaro estar debiendo a Don Mathías Conde, vecino de dicha ciudad de Santiago, ochocientos reales vellón; a Don Benito de Pazos, de la misma vecindad, a mi parecer, ciento quarenta y cinco de dicho vellón; a Don Manuel Phelipe, secretario de la Universidad de dicha ciudad, ducientos setenta y dos reales, importe de dos quintales de bacalao; y a don Thomás Vaamonde, mercader, dos quartas y media de terciopelo, cuyos débitos, quiero se paguen a costa de mis bienes.

Débeme el zapatero Carlos Buelta, alias Carlín, tres pares de suela de concha, e yo le debo quatro reales vellón.

$Y$ porque al presente no puedo hacer memoria de lo más que me deban e yo sea deudor, quiero, y es mi voluntad, que todo lo que legítimamente conste en una y otra forma sea cobrado y pagado, para descargo de mi conciencia.

También declaro haber estado casado de primer matrimonio con Pasqua Gonzales de la Iglesia, del que tuvimos por nuestro hijo a Pedro Antonio Sarela, el que superviviendo a la madre, murió a la hedad de nueve años poco más, o menos; y de segundo matrimonio, hay algunos años, estoy cassado con Doña Benita de Castro, del que tenemos, criamos, y educamos por nuestros hijos a Fulgencio, y María Francisca Sarela de Castro, que esta se halla en hedad de dos años, y aquel en la de quatro, a los quales nombro, y elijo por su tutora y curadora a la referida doña Benita de Castro, su madre, teniendo presente la ternura de su cariño, con que los ama, cuyda, y educa assistiéndome el consuelo y confianza de su proceder, no hará menos a lo adelante por su ascendosso y económico de su experimentado govierno, a la que dexo relevada de fianza en todo lo que pueda, tenga arbitrio, y por derecho me sea permitido; $y$ encargo a dichos mis dos hijos la obedescan y, en más hedad, la den el tratamiento, como a madre que se lo merece, respetosamente, cuydándola y assistiéndola en todo lo que se le ofresca y necessite, como hijos de bendición, a quienes después de Dios Nuestro Señor, a quien pido me encomienden, les dexo quedar la mía, y encargado a Don Fulgencio de Castro, su abuelo, y a Don Juán Zarela, mi hermano, cathedrático de 
philosophía en dicha Universidad de Santiago, los miren según asta aquí cariñosamente lo han hecho, ayudando a los trabajos y casualidades que ocurran a su madre, y a esta pido perdón de algunos disgustos casseros que en el discurso de nuestro matrimonio pudieron acontecer y ofrecerse, y que también me encomiende a Dios.

Nombro por mis cumplidores, y alvaceas de este mi testamento y última voluntad a la citada Doña Benita de Castro, mi muger, a Don Fulgencio de Castro, mi suegro, a mi querido hermano dicho cathedrático Don Juan Zarela, y a mi especial y cordial amigo Don Andrés Varela del Corral, presvitero y cofrade de Nuestra Señora de la Concepción, inclusa en la Santa y Apostólica Yglesia de dicha ciudad de Santiago, para que a costa de mis bienes, y con la brevedad que les sea possible, cumplan y hagan cumplir todo lo aquí por mi dispuesto. A cuyo fin, les otorgo el poder suficiente en causa propia.

$Y$ en todo lo más remanente de mis bienes, deudas, derechos, y acciones instituyo por mis universales herederos, a los referidos Fulgencio, y María Francisca Sarela de Castro, mis dos hijos, para que por mitad los lleven y gozen por siempre con la bendición de Dios y la mía, que les repito. Con lo que revoco y anulo cualquier testamento u codicilio, última voluntad, que hayga hecho por escrito u verbal, que quiero no valga en juicio ni fuera del, excepto este, que hago y otorgo en esta mi cassa de habitación del barrio citado Carrera del Conde, parroquia de Santa Susana de Adentro, a diez días del mes de julio de mil sietecientos y sessenta y dos, por ante el presente escrivano y testigos, a uno de los que, porque la enfermedad que padezco no me permite el usso para firmar, ruego lo haga por mí de su nombre, según a todo ello lo fueron presenciales, Jacobo de la Yglesia, Luis Parcero, Francisco García Guevara, Pedro Benito Rodríguez Varreyro y Matheo García de Lamas, vecinos de dicha parroquia de Santa Susana; de todo lo que conocimiento del otorgante y este hallarse con caval juicio y entendimiento natural por lo concertado de sus razones, trato, conocimiento de mí escrivano, y dichos testigos, doy fee. Entre líneas: su; se; so. Vala. Como testigo y a ruego, Jacobo de la yglesia. Ante mi, Manuel Garzía.

"CUADERNOS DE ESTUdiOS GALLEGOS", Tomo XLV, Fascículo 110, Santiago 1998. 